\title{
Inactivation of Escherichia coli in Tender Coconut (Cocos Nucifera L.) Water by Pulsed Light Treatment
}

\author{
P. Preetha ${ }^{1 *}$, Arun Prasath Venugopal ${ }^{1}$, N. Varadharaju ${ }^{2}$ and Z. John Kennedy ${ }^{2}$ \\ ${ }^{1}$ Department of Food and Agricultural Process Engineering, ${ }^{2}$ Post-Harvest Technology Centre, \\ AEC \& RI, Tamil Nadu Agricultural University, \\ Coimbatore-641 003, Tamil Nadu, India \\ *Corresponding author
}

\section{A B S T R A C T}

\begin{tabular}{l} 
K e y w o r d s \\
Pulsed light, \\
Tender coconut, \\
Process parameter, \\
$\begin{array}{l}\text { E. coli } \\
\text { inactivation. }\end{array}$ \\
\hline Article Info \\
$\begin{array}{l}\text { Accepted: } \\
\text { 19 June } 2017 \\
\text { Available Online: } \\
\text { 10 July } 2017\end{array}$ \\
\hline
\end{tabular}

\section{Introduction}

Coconut palm (Cocos nucifera $L$ ), originally native from Southeast Asia and Melanesia Islands in the Pacific Ocean, has been introduced into all tropical and subtropical world regions. World's major coconut production lies between $20 \mathrm{~N}$ and $20 \mathrm{~S}$ latitudes in six primary areas: Philippines, India, Indonesia, Sri Lanka, South Sea Islands and Malaysia.

India is one of the leading producers of coconuts in the world producing 13 billion nuts per annum. The area is distributed in 18 states and three Union Territories under different agro climatic conditions and a 3000 years tradition in coconut cultivation. About $48 \%$ of the total production of coconut in the country is used for edible and religious purposes, $31 \%$ for conversion into mill copra, $8 \%$ for the production of edible copra, $11 \%$ as tender coconut water and the balance is used to manufacture of dry coconut powder, coconut cream and other products (Arumughan et al., 1995).

Tender coconut water is the juice in the endosperm of young coconut. The water is one of the nature's most refreshing drinks consumed worldwide for its nutritious and health benefiting properties (Fonseca et al., 
2009). Young and slightly immature nuts with a maturity of 5-7 months are harvested for this purpose. Each nut may contain about 200 to $1000 \mathrm{ml}$ of water depending on cultivar type and size. Tender coconut water contains the minerals such as potassium, sodium, calcium, phosphorous, iron, copper, sulphur and chlorides (Nadanasabapathy and Kumar, 1999). It is also believed that coconut water could be used as an important alternative for oral rehydration and even so for intravenous hydration of patients in remote regions (Cambell-Falck et al., 2000). Regular consumption of either coconut water is effective in bringing about the control of hypertension (Alleyne et al., 2005). People suffering from stomach pain and vomiting get relief by drinking coconut water (Hegde, 2011). Coconut water may also offer protection against myocardial infarction (Anuraj and RajaMohan, 2003).

The tender coconut cannot be stored for more than a week at room temperature because of fungal attack to the perianth limiting their distribution from production regions to consumers unless processed in to stabilized products. When the coconut water comes in contact with the oxygen, enzymes present in it such as polyphenol oxidase (PPO) and peroxidase (POD) begin reaction and modify the typical food properties, causing nutritional and color losses (Matsui et al., 2008).

Thermal technologies such as pasteurization, sterilization, concentration by evaporation, spray drying are widely carried out to control microbial spoilage and inactivate microbial pathogens. However, these treatments have negative effects reducing including vitamin content reduction, degradation of volatile flavor compounds, denaturation of protein and other nutrients, and undesirable changes in sensory features including color and rheological properties (Elmnaser et al., 2008). Non-thermal technologies such as pulsed light are treatment alternatives that are developed to obtain final product $\mathrm{s}$ with a superior sensory quality, while ensuring microbial safety (FDA/CFSAN report, 2000; Woodling and Moraru, 2005).

Pulsed light (PL) was developed to decontaminate surfaces by using intense short time pulses of light with a broad spectrum. The emitted light flash has a high peak power and consists of wavelengths from 200 to 1100 nm (Dunn et al., 1997) which includes Ultraviolet light, broad spectrum white light and near infrared light (Green et al., 2005). Therefore the aim of this research was to develop pulsed light system for food processing applications to retain the nutrient and sensory properties of the coconut juice and thereby satisfying the consumer demand for 'wholesome, fresh like foods'. The pulse light treatment conditions studied were juice layer depth, shelf height of the beam source, number of pulses and fluence values.

\section{Materials and Methods}

\section{Extraction of tender coconut water}

Matured tender coconut was purchased from the local market. The surface sterilization was done with 70 percent ethanol solution (Awua et al., 2011). The endosperm was cutted with sharp sterilized knife and the water was transferred in to a sterile reagent bottle capacity $(1000 \mathrm{ml})$. The volume of water collected in these bottles from each coconut ranged from 360 to $500 \mathrm{ml}$.

\section{Inoculation of $E$. coli culture}

E. coli culture (obtained from MTCC) was grown in nutrient agar (NA) medium plates at $37^{\circ} \mathrm{C}$ for $24 \mathrm{~h}$. Stationery phase cultures typically reached a final approximate concentration of $10^{9} \mathrm{cfu} / \mathrm{ml}$. Cells are collected by centrifugation (Rotor no. A4-44 producing a relative centrifugal force 10,375 ) at 
room temperature and rinsing with $0.1 \%$ peptone prior to inoculation in to juices at an initial level of concentration approximately at $10^{6} \mathrm{cfu} / \mathrm{ml}$. A working culture was prepared by aseptically transferring a colony from the NA plates in to fresh NA broth that was again incubated at $37^{\circ} \mathrm{C}$ for $24 \mathrm{~h}$. For inoculation to coconut water at final concentration of $\leq 10^{7} \mathrm{cfu} / \mathrm{ml}$ culture was added directly.

\section{Sterilization of tender coconut water}

Pulsed light treatment were carried out using an laboratory system (Batch) (Figure 1) equipped with standard clear $75 \mathrm{~mm}$ long transparent quartz Xenon Lamp (Make: Hereus Noblelight Ltd., U.K.) which had a bore diameter of $3 \mathrm{~mm}$. The emitted spectrum ranged from 180 to $1100 \mathrm{~nm}$. Pulse width of 40 micro second.

The fresh tender coconut water was autoclaved at $121^{\circ} \mathrm{C}$ at 1.5 bar for 15 minutes. The volume of water obtained ranges from average 360 to $500 \mathrm{ml}$. The sterilized juice sample was inoculated to E. coli of $10^{6}$ to $10^{7} \mathrm{cfu} / \mathrm{ml}$ and placed inside the treatment chamber in a petri dish (100mm diameter) and the door was closed. The samples are exposed to receive $0.08 \mathrm{~J} / \mathrm{cm}^{2}$ per pulse. The treatment of 60 , $120,180,240$ flashes thus resulting in an overall fluence in the range of 4.8, 9.6, 14.4 and $19.2 \mathrm{~J} / \mathrm{cm}^{2}$. The treated samples were covered carefully transferred to aseptic laminar air flow chamber where they were bottled in glass bottles $(100 \mathrm{ml})$ for shelf life study. The treated samples were stored at $8 \pm 2^{\circ} \mathrm{C}$ to determine the shelf life.

\section{Quality characteristics}

The total soluble solids was determined using a digital hand held refractometer (Atago co., Ltd., Tokyo, Japan) and the total soluble solid content was expressed as ${ }^{\circ}$ Brix at $25^{\circ} \mathrm{C}$. The $\mathrm{pH}$ of juice was measured using digital $\mathrm{pH}$ meter (Cyber scan, India) at $25^{\circ} \mathrm{C}$. Clarity was determined by measuring the transmittance at $\lambda=610 \mathrm{~nm}$ using a UV-VIS Double beam spectrophotometer 2202 (Systronics).

The colour of juice was measured using a Hunter lab colour flux meter (Hunter Associate Laboratory, Inc., Reston) which provides colour values in the terms of $\mathrm{L}$, a, and $b$, where $L$ indicates whiteness to darkness, a (+) redness, a (-) greenness, b(+) yellowness and $b(-)$ blueness.

$\Delta \mathrm{E}=\left(\Delta \mathrm{a}^{2}+\Delta \mathrm{b}^{2}+\Delta \mathrm{L}^{2}\right)^{1 / 2}$

\section{Statistical analysis}

The experimental design was taken to optimize the number of flashes to the sample 120, 180 and 240 flashes, shelf height from the lamp- 5, 10 and $15 \mathrm{~cm}$ from the lamp, juice layer depth - 5, 10, 15 and 20mm.

All the experiments were carried out in triplicates. General Linear model of Multivariate analysis was carried out to study the effect of independent parameters on the dependent variable such as no of fluence, shelf height and depth of the juice. Using a software SPSS version 20 (IBM).

\section{Results and Discussion}

\section{Inactivation of $E$. coli}

\section{Effect of fluence on the inactivation of $E$. coli}

Higher intensity had a greater reduction in the E. coli is shown in figure 2. Log reduction achieved after PL treatment with a fluence of $4.8 \mathrm{~J} / \mathrm{cm}^{2}$ ranged from $3.4 \mathrm{log} \mathrm{CFU} / \mathrm{ml}$ where delivered maximum energy of $19.2 \mathrm{~J} / \mathrm{cm}^{2}$ to $5.2 \log$ reduction. The energy for one pulse was $0.08 \mathrm{~J} / \mathrm{cm}^{2}$ whereas for $60,120,180$ and 240 pulses delivered a $4.8 \mathrm{~J} / \mathrm{cm}^{2}, 9.6 \mathrm{~J} / \mathrm{cm}^{2}$, 
$14.4 \mathrm{~J} / \mathrm{cm}^{2}$ and $19.2 \mathrm{~J} / \mathrm{cm}^{2}$. A maximum $\log$ reduction of 5.2 can be achieved using the pulsed light technology when a fluence of $19.2 \mathrm{~J} / \mathrm{cm}^{2}$ was applied for tender coconut water. FDA has recommended that at least a 5 $\log$ reduction of more resistant microorganism under specific operating conditions (US FDA, 2001, 2004).

By the differing number of pulses, reduction in $E$. coli had a significant effect $(\mathrm{p}<0.05)$. The sensitivity of the micro-organism to PUV depends on the protein present in the material that absorbs the UV light (Koutchma, 2009). Huffman et al., 2000 treated water at 0.25 $\mathrm{J} / \mathrm{cm} 2$ gave a reduction of $>7.4 \log 10 \mathrm{cfu} / \mathrm{ml}$ for Klebsiella terrigena after two pulse. These results showed that transparency of the media allowed successful microbial inactivation using this technology.

Sauer and Moraru (2009) studied the effect of PL treatment in liquid foods with different in the level of clarity such as butterfield's phosphate buffer, tryptic soy broth, apple juice and apple cider. They found that susceptibility decreased based on clarity.

\section{Effect of depth of juice on the inactivation of $E$. coli}

Figure 3 presents the effect of depth of the tender coconut water on the inactivation of $E$. coli treated at a distance of $15 \mathrm{~cm}$. Statistical analysis demonstrated significant differences between the inactivation of $E$. coli using different juice depth levels ( $\mathrm{p}<0.05)$. A 4.5 $\log$ reduction was observed for a dose of 19.2 $\mathrm{J} / \mathrm{cm}^{2}$ at the smallest juice depth of $5 \mathrm{~mm}$.

Decreasing the juice depth from $5 \mathrm{~mm}, 10 \mathrm{~mm}$, $15 \mathrm{~mm}$ and $20 \mathrm{~mm}$ at fluence levels of $4.8,9.6$, 14.4 and $19.2 \mathrm{~J} / \mathrm{cm}^{2}$, inactivation efficiency increased to a maximum reduction of $2.7,3.1$, 3.6 and $4.5 \log$ reductions. In juice products, $90 \%$ of light absorption occurs at a depth of $\mathrm{x}$ $\mathrm{mm}$ (Keyser et al., 2008). Figure 3 shows that increasing the depth of the juice reduced the microbial reduction level achieved.

At a $20 \mathrm{~mm}$ juice depth, only $3.7 \mathrm{log}$ reductions were achieved at a maximum fluence of $19.2 \mathrm{~J} / \mathrm{cm}^{2}$.This may be due to the absorption capacity of the juice is found to be well more critical factor influencing the PL treatment (Maftei et al., 2014).

Microbial destruction obtained by this study are consistent with those other researcher obtained in different media. Hillegas and Demirci (2003) reported that $2 \mathrm{~mm}$ layer depth of honey had a 73.9 per cent reduction in the count of Clostridium sporogenes spores whereas for $8 \mathrm{~mm}$ it had only 14.2 per cent.

\section{Influence of the distance from the lamp on the Inactivation of $E$. coli}

Inactivation of $E$. coli in the tender coconut processed by PL at different shelf height is shown in figure 4. At a fluence of maximum $19.2 \mathrm{~J} / \mathrm{cm} 2$ dose, there exhibit a $5.2 \mathrm{log}$ reduction at a nearer distance of $5 \mathrm{~cm}$ from the lamp.

By increasing the distance the lamp, the absorption of light to the sample gets reduced, so there was only $4.9,4.5 \log$ reduction at a distance of $10 \mathrm{~cm}$ and $15 \mathrm{~cm}$.

The microbial inactivation was higher at the distance of $5 \mathrm{~cm}$, this may be due to the more absorption of the light rays to the sample. Similar results are obtained by the Hillegas and Demirci (2003) for honey treating at a distance of $20 \mathrm{~cm}$, achieved 73.9 reduction of Clostridium sporogenes with a minimum depth of $2 \mathrm{~mm}$ of honey. Microbial inactivation had a statistically significant ( $\mathrm{p}<$ 0.05 ) effect on the difference in the distance from the lamp. 
Table.1 Physico-chemical characteristics of pulsed light treated tender coconut water

\begin{tabular}{|c|c|c|c|c|c|}
\hline Shelf height & Flashes & Depth of the juice & pH & TSS & Colour \\
\hline \multirow{12}{*}{$5 \mathrm{~cm}$} & \multirow{4}{*}{120} & $5 \mathrm{~mm}$ & 4.98 & 3.7 & 0.43 \\
\hline & & $10 \mathrm{~mm}$ & 4.99 & 3.71 & 0.51 \\
\hline & & $15 \mathrm{~mm}$ & 5.02 & 3.72 & 0.56 \\
\hline & & $20 \mathrm{~mm}$ & 5.04 & 3.72 & 0.6 \\
\hline & \multirow{4}{*}{180} & $5 \mathrm{~mm}$ & 4.94 & 3.72 & 0.46 \\
\hline & & $10 \mathrm{~mm}$ & 4.96 & 3.72 & 0.52 \\
\hline & & $15 \mathrm{~mm}$ & 4.98 & 3.74 & 0.59 \\
\hline & & $20 \mathrm{~mm}$ & 5.01 & 3.74 & 0.63 \\
\hline & \multirow{4}{*}{240} & $5 \mathrm{~mm}$ & 4.93 & 3.73 & 0.47 \\
\hline & & $10 \mathrm{~mm}$ & 4.95 & 3.73 & 0.56 \\
\hline & & $15 \mathrm{~mm}$ & 4.96 & 3.74 & 0.64 \\
\hline & & $20 \mathrm{~mm}$ & 4.98 & 3.75 & 0.68 \\
\hline \multirow{12}{*}{$10 \mathrm{~cm}$} & \multirow{4}{*}{120} & $5 \mathrm{~mm}$ & 5.04 & 3.74 & 0.14 \\
\hline & & $10 \mathrm{~mm}$ & 5.06 & 3.74 & 0.24 \\
\hline & & $15 \mathrm{~mm}$ & 5.06 & 3.76 & 0.37 \\
\hline & & $20 \mathrm{~mm}$ & 5.07 & 3.78 & 0.41 \\
\hline & \multirow{4}{*}{180} & $5 \mathrm{~mm}$ & 5.04 & 3.72 & 0.16 \\
\hline & & $10 \mathrm{~mm}$ & 5.04 & 3.72 & 0.21 \\
\hline & & $15 \mathrm{~mm}$ & 5.05 & 3.74 & 0.33 \\
\hline & & $20 \mathrm{~mm}$ & 5.07 & 3.76 & 0.43 \\
\hline & \multirow{4}{*}{240} & $5 \mathrm{~mm}$ & 4.97 & 3.7 & 0.36 \\
\hline & & $10 \mathrm{~mm}$ & 4.98 & 3.72 & 0.44 \\
\hline & & $15 \mathrm{~mm}$ & 5.02 & 3.73 & 0.48 \\
\hline & & $20 \mathrm{~mm}$ & 5.04 & 3.74 & 0.52 \\
\hline \multirow{12}{*}{$15 \mathrm{~cm}$} & \multirow{4}{*}{120} & $5 \mathrm{~mm}$ & 5.07 & 3.76 & 0.4 \\
\hline & & $10 \mathrm{~mm}$ & 5.07 & 3.78 & 0.46 \\
\hline & & $15 \mathrm{~mm}$ & 5.08 & 3.8 & 0.54 \\
\hline & & $20 \mathrm{~mm}$ & 5.08 & 3.8 & 0.62 \\
\hline & \multirow{4}{*}{180} & $5 \mathrm{~mm}$ & 5.05 & 3.74 & 0.52 \\
\hline & & $10 \mathrm{~mm}$ & 5.06 & 3.75 & 0.56 \\
\hline & & $15 \mathrm{~mm}$ & 5.07 & 3.77 & 0.66 \\
\hline & & $20 \mathrm{~mm}$ & 5.07 & 3.78 & 0.75 \\
\hline & \multirow{4}{*}{240} & $5 \mathrm{~mm}$ & 5.02 & 3.7 & 0.46 \\
\hline & & $10 \mathrm{~mm}$ & 5.03 & 3.74 & 0.52 \\
\hline & & $15 \mathrm{~mm}$ & 5.03 & 3.74 & 0.56 \\
\hline & & $20 \mathrm{~mm}$ & 5.04 & 3.76 & 0.58 \\
\hline
\end{tabular}


Fig.1 Schematic diagram of laboratory models pulsed light apparatus

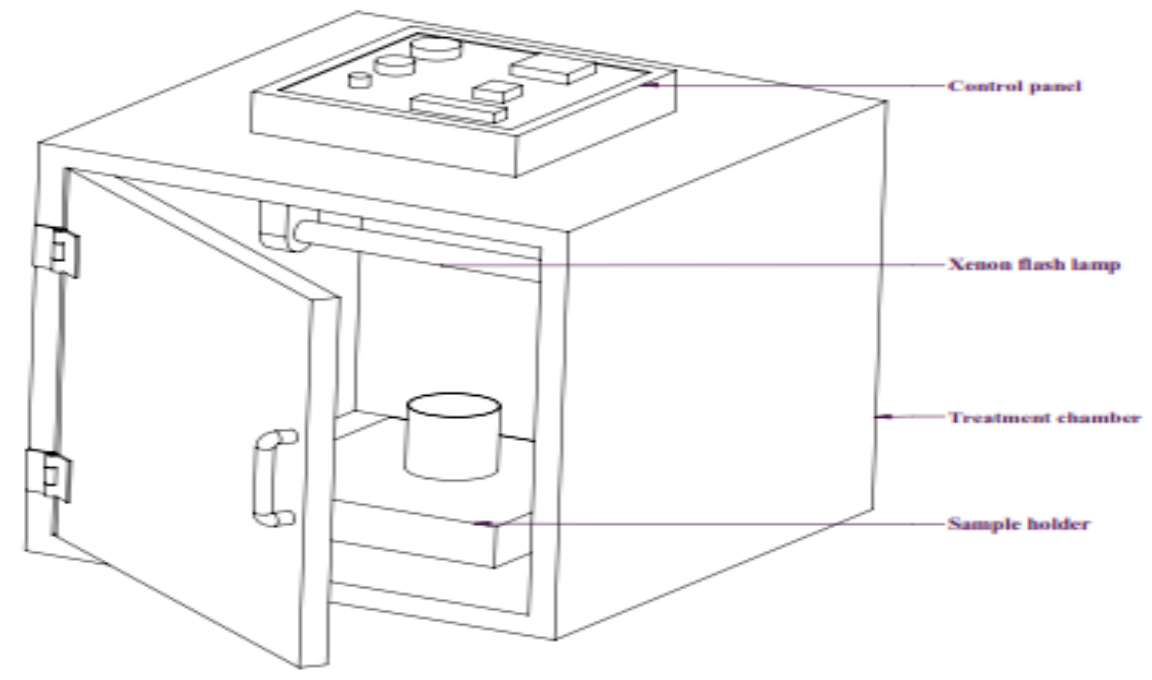

Fig.2 Influence of fluence on the inactivation of E. coli

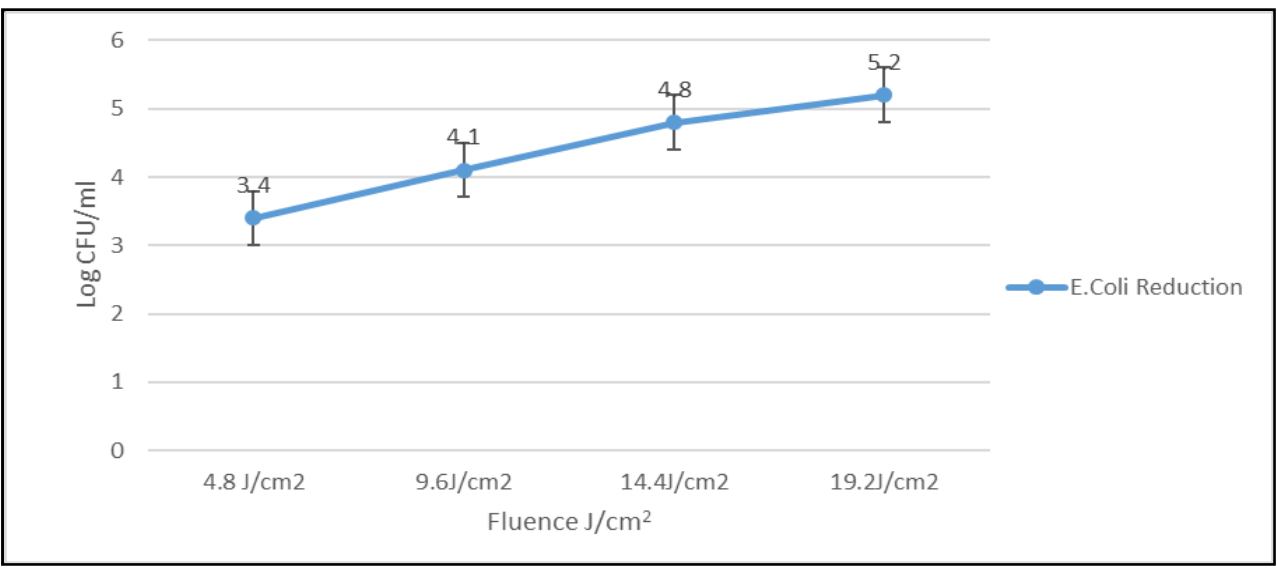

Fig.3 Influence of depth of the juice $(\mathrm{mm})$ in the inactivation of E. coli at a distance of $15 \mathrm{~cm}$ from the lamp

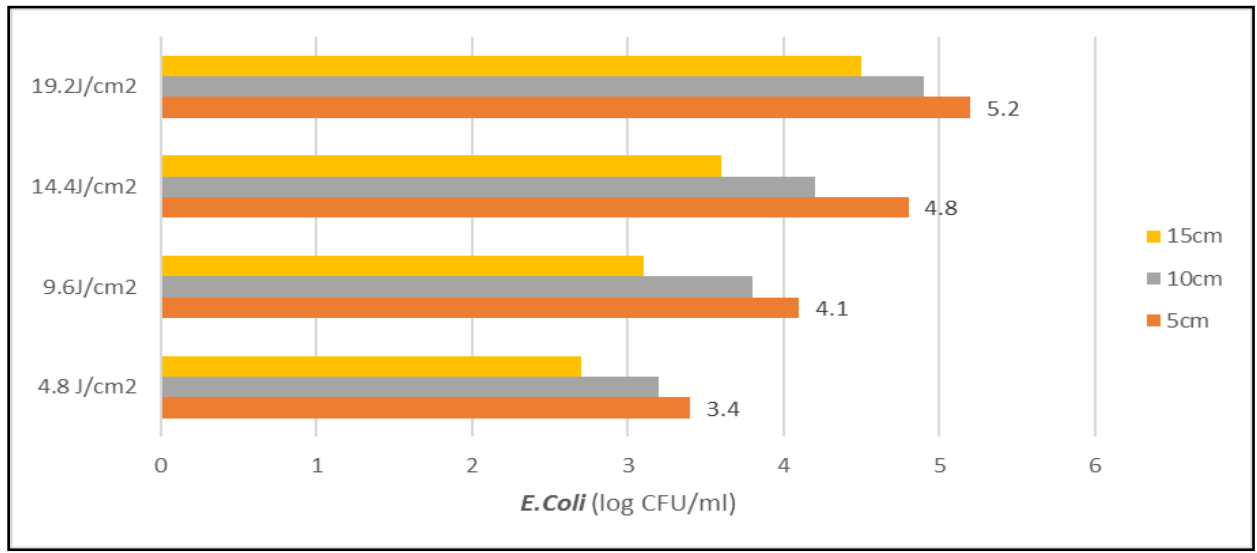


Fig.4 Influence of distance from the lamp on the inactivation of $E$. coli with a $5 \mathrm{~mm}$ depth of tender coconut

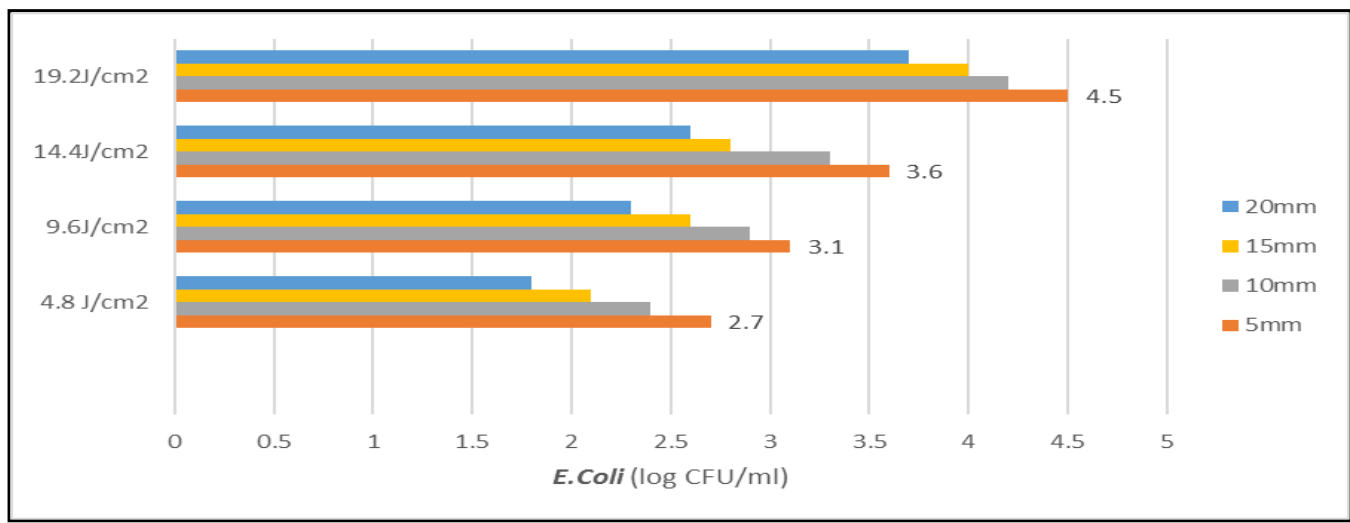

Physico - chemical properties of PL treated tender coconut water

Soluble solids and $\mathrm{pH}$ of the tender coconut water did not show statistical difference $(\mathrm{p}<0.05)$ after testing in different process parameter of Pulsed light treatment which is in agreement with Choi et al., (2002) and Francis and Clydesdale (1975) for orange juice. The results are presented in table 1 . In broader spectrum of PL, the liquid food does not have any quality changes (Oms-Oliu et al., 2008). Tender coconut treated with maximum pulses of 240 had a slight change in $\mathrm{pH}$ and soluble solids. Similar trend of results are obtained by Kashara et al., (2004) on clarified apple juice, which is exposed to different energy doses and analysed for TSS, $\mathrm{pH}$, color and viscosity. Color measurements are also performed in this study. The PL treatment does not cause statistically different $(p<0.05)$ browning effect in tender coconut water. This was conformed based on the instrumental measurement of lightness. Palgan et al., (2011) also reported for apple juice, it does not cause any browning after pulsed light treatment. Samples treated with a maximum energy (240 flashes) at minimum distance of $5 \mathrm{~cm}$ from the lamp with a depth of $5 \mathrm{~mm}$ of tender coconut water does not exhibit a color change of greater than 0.5.
These results are compared to Mafeti et al., (2014) who studied for apple juice, those obtain only minor changes in the $\mathrm{pH}$ and soluble solids, however the apple juice color slightly darkened after applying a $32 \mathrm{~J} / \mathrm{cm}^{2}$ but the total color differences are not greater than 0.5

In similar to our results, Noci et al., (2008) also noticed, after PL treatment in apple juice does not have any noticeable change in $\mathrm{pH}$ and soluble solids. The different energy doses applied to clarified apple juice did not cause significant difference in terms of soluble solids and colour (Kasahara et al., 2004). The instrumental measurement of color for apple juice treated with pulsed light had showed a slightly noticeable change by applying a fluence of $28 \mathrm{~J} / \mathrm{cm}^{2}$ (Palagan et al., 2011). Case by case analysis is need with different equipment and food samples.

In conclusion, the process parameters also play a major role in controlling the $E$. coli in tender coconut water. The minimum depth $(2 \mathrm{~mm})$, nearer distance $(5 \mathrm{~cm})$ and higher number of pulse (240 flashes) can achieve more inactivation. Pulsed light technology does not affect the quality parameters of the tender coconut water when it is treated with different process parameter. Hence this study 
is useful in preserving liquid foods using pulsed light. This could be an alternative technology for thermal processing.

\section{References}

Anurag, P. and Rajamohan, T. 2003. Cardioprotective effect of tender coconut water in experimental myocardial infarction. Plant Foods. Hum. Nutr. 58: 1-12.

Alleyne, T., Roache, S., Thomas, C. and Shirley, A. 2005. The control of hypertension by use of coconut water and mauby: Two tropical food drinks. West Indian Med. J. 54: 3-8.

Arumughan, C., Balachandran, C. and Sundaresan, A. 1995. Development of a Process for Coconut cream on Commercial scale. Journal of Food Science and Technology. 3: 408-412.

Awua, A. K., Doe, E. D. and Agyare, R. 2011. Exploring the influence of sterilization and storage on some physicochemical properties of coconut (Cocos nucifera L.) water. BMC Research Note. 4: 451.

Campbell-Falck, D., Thomas, T., Falck, T. M., Tutuo, N. and Clem, K. 2000. The intravenous use of coconut water. Am. J. Emerg. Med. 18: 108-111.

Choi, M. H., Kim, G. H. and Lee, H. S. 2002. Effects of ascorbic acid retention on juice color and pigment stability in blood orange (Citrus sinensis) juice during refrigerated storage. Food Research International. 35(8): 753-759.

Dunn, J., Bushnell, A., Ott, T. and Clark, W. 1997. Pulsed white light food processing. Cereal Foods World. 42: 510-515.

Elmnasser, N., Dalgalarrondo, M., Orange, N., Bakhrouf, A., Haertlé, T., Federighi, M., and Chobert, J. M. 2008. Effect of pulsed-light treatment on milk proteins and lipids. Journal of Agricultural and
Food Chemistry. 56: 1984-1991.

FDA/CFSAN. 2000. Kinetics of microbial inactivation for alternative food processing technologies: Pulsed light technology. Center for Food Safety and Nutrition.

Fonseca, A. M., Monte, F.J.Q., Conceic, M. and Oliveiraaão, F. 2009. Coconut water (Cocos nucifera L.) - A new biocatalyst system for organic synthesis. Journal of Molecular Catalysis B: Enzymatic. 57: 78-82.

Francis, F. J. and Clydesdale, F. M. 1975. Food colorimetry: Theory and applications. Westport: AVI Publishing Company.

Green, S., Basaran, N. and Swanson, B. 2005. Food preservation techniques. In Zenthen, P. and Bogh Sorenson, L. (Eds). Washington, United States of America: Woodhead Publishing House. 365. CRC press.

Hegde, B. M. 2011. Coconut -the best food for human beings' health and longevity. Indian Coconut Journal. 13-14.

Hillegas, S. L. and Demirci. A. 2003. Inactivation of Clostridium sporogenes in clover honey by pulsed UV-light treatment. Agricultural Engineering International: the CIGR Journal of $A E$ Scientific Research and Development. 7: 03-009.

Huffman, D. E., Slifko, T. R., Salisbury, K. and Rose, J. B. 2000. Inactivation of bacteria, virus and Cryptosporidium by a point-of-use device using pulsed broad spectrum white light. Water Research. 34: 2491-2498.

Kasahara, I., Kaiser, S., Aguilar, F. and Marillanca, M. 2004. Pasteurisation of apple juice by pulsed ultraviolet light: processing conditions and effect in the product characteristics. In Proceedings of the International Conference Engineering and Food, Montpellier, France. 
Keyser, M., Muller, I. A., Cilliers, F. P., Nel, W. and Gouws, P. A. 2008. Ultraviolet radiation as a non-thermal treatment for the inactivation of microorganisms in fruit juice. Innovative Food Science and Emerging Technologies. 9: 348-354.

Koutchma, T. 2008. UV light for processing foods. Ozone Science and Engineering., 30: 93-98.

Mafeti, N. A., Ramos, A. Y. V., Nicolau, A. I., Martin-Belloso, O., Soliva-Fortuny, R. 2014. Influence of process parameters on the pulsed light inactivation of Penicillin expansum in apple juice. Food Control. 41: 27-31.

Matsui, K. N., Gut, J. A. W., Oliveira, P. V. and Tadini, C. C. 2008. Inactivation kinetics of polyphenol oxidase and peroxidase in green coconut water by microwave processing. Journal of Food Engineering. 88: 169-176.

Nadanasabapathy, S. and Kumar, R. 1999. Physico-chemical constituents of tender coconut (Cocos nucifera) water. Indian Journal of Agricultural Science. 69: 750-751

Noci, F., Riener, J., Walkling-Ribeiro, M., Cronin, D. A., Morgan, D. J. and Lyng, J. G. 2008. Ultraviolet irradiation and pulsed electric fields (PEF) in a hurdle strategy for the preservation of fresh apple Juice. Journal of Food Engineering. 85(1): 141-146.

Oms-Oliu, G., Martín-Belloso, O. and SolivaFortuny, R. 2008. Pulsed light treatments for food preservation: a review. Food and Bioprocess Technology.

Palagan, I., Caminiti, I. M., Muñoz, A., Noci, F., Whyte, P., Morgan, D. J., Cronin, D. A. and Lyng, J. G. 2011. Effectiveness of High Intensity Light Pulses (HILP) treatments for the control of Escherichia coli and Listeria innocula in apple juice, orange juice and milk. Food microbiology. 28: 14-20.

Sauer, A. and Moraru C. I. 2009. Inactivation of Escherichia coli ATCC 25922 and Escherichia coli $\mathrm{O} 157: \mathrm{H7}$ in apple juice and apple cider, using pulsed light treatment. Journal of Food Protection. 72: 37-944.

US FDA, 2001. Hazard Analysis and Critical Control Point (HACCP): Procedures for the Safe and Sanitary Processing and Importing of Juice: Final rule. Office of the Federal Register, National Archives and Records Administration.

US FDA, 2004. Guidance for Industry, Juice HACCP Hazards and Controls Guidance. Office of the Federal Register, National Archives and Records Administration.

Woodling, S. E. and Moraru, C. I. 2005. Influence of surface topography on the effectiveness of pulsed light treatment for the inactivation of Listeria innocula on stainless steel surfaces. Journal of Food Science. 70(7): M345-M351.

\section{How to cite this article:}

Preetha, P., Arun Prasath Venugopal, N. Varadharaju and John Kennedy, Z. 2017. Inactivation of Escherichia coli in Tender Coconut (Cocos Nucifera L.) Water by Pulsed Light Treatment. Int.J.Curr.Microbiol.App.Sci. 6(7): 1453-1461. doi: https://doi.org/10.20546/ijcmas.2017.607.174 